\title{
ANALISIS KARYA SENI BERTEMAKAN TOILET DALAM PANDANGAN TEORI ESTETIKA SEHARI-HARI
}

\author{
Nurulfatmi Amzy \\ Desain Komunikasi Visual, Universitas Indraprasta PGRI Jakarta \\ nurulfatmiamzy@gmail.com
}

\begin{abstract}
Abstrak
Ada banyak karya seni yang hadir di ruang publik, ternyata tidak semuanya memberikan rasa nyaman bagi penikmatnya. Ada juga karya seni yang mengundang perasaan jijik dan muak sebagian orang, sehingga dinilai sebagai karya seni yang kontroversial. Karya seni semacam itu dapat ditemui di Mr. Toilet House, sebuah museum dengan area terbuka yang dipenuhi instalasi seni bertema toilet. Meskipun dinilai menjijikkan oleh sebagian orang, tempat itu tetap ramai dikunjungi. Artikel ini akan membahas karya seni yang bertemakan toilet tersebut dengan pendekatan teori estetika sehari-sehari, di antaranya estetika sosial dan teori disgust. Analisis ini menggunakan fenomenologi sebagai metode penelitian. Artikel ini akan memaparkan bahwa ada banyak persepsi tentang seni dalam masyarakat, namun itu bukan alasan untuk mengadakan sebuah pembatasan dan pengeksklusifan terhadap seni yang boleh diapresiasi. Estetika sosial menyadari bahwa semua karya seni patut untuk ditampilkan dan diapresiasi.
\end{abstract}

Kata Kunci: Karya seni, toilet, estetika sehari-hari, estetika sosial, disgust.

\begin{abstract}
There are many artworks build in public spaces, but not all of them comfort the audience. Some artwork provokes feelings of disgust for some people, so it is considered controversial artwork. Such as Mr. Toilet House. It is a museum with a park filled with toilet-themed art installations. Even though some people find it disgusting, the place is still full of visitors. This article will discuss toilet-themed artworks based on the aesthetics of everyday life theory. This analysis uses phenomenology as a research method. This article will explain that there are many perceptions of art in our society. However, that is not a reason to make a limitation and exclusion of art that can be appreciated. Social aesthetics recognize that all works of art deserve to be displayed and appreciated
\end{abstract}

Keywords: Artwork, toilet, aesthetics of everyday life, social aesthetics, disgust

Correspondence author: Nurulfatmi Amzy, nurulfatmiamzy@gmail.com, Jakarta, and Indonesia 


\section{PENDAHULUAN}

"Cara agar hunian Anda menjadi lebih estetik", "9 Wisata Pohon Natal Paling Estetik di Dunia," dan "6 kunci feed Instagram lebih estetik" adalah judul-judul yang ditemui pada laman berita popular daring. Ketiga judul tersebut mengandung kata estetik, yang mengarah kepada kata indah. Pembicaraan tentang seni, seperti yang tersirat dalam judul-judul artikel tersebut, memang erat kaitannya dengan kata estetik. Hanya saja, anggapan bahwa estetik bermakna indah sepertinya perlu dikaji ulang.

Ekosiwi dalam tulisannya yang berjudul Permasalahan Etis Dalam Estetika Dan Pendidikan Filsafat Seni (2017) menjelaskan bahwa estetika merupakan pengenalan sistem indrawi manusia terhadap segala objek yang mampu ditangkap oleh indra. Maka, estetika tidak hanya menyoal objek yang bisa dilihat dan didengar, namun juga dikecap, diraba, serta dicium. Proses pengenalan objek tersebut akan menghasilkan pengetahuan dan pengalaman estetik. Pengalaman estetik mencakup semua sensasi yang ditangkap indra secara murni, seperti indah, sedih, marah, jijik benci dan lain sebagainya. Singkatnya, estetika tidak melulu bicara soal keindahan.

Dengan demikian, jika kata 'estetik' perlu disematkan dalam sebuah penilaian karya seni, maka karya seni tersebut tidak harus selalu indah. Apabila sebuah karya seni dapat menarik perhatian dengan rasa jijik dan kemuakan yang ditimbulkannya, karya seni tersebut juga patut disebut sebagai karya seni bernilai estetik. Pemahaman bahwa karya seni tidak selalu menghasilkan keindahan ini melandasi Rudiman (2014) merancang video instalasi dengan tubuh dan organ tubuh manusia sebagai objeknya. Video tersebut dirancang dalam nuansa medis. Rudiman mengutarakan bahwa ada kecenderungan dalam diri manusia untuk merasa takut dan terganggu terhadap penggambaran tubuh berserta sistem organnya. Ia mengolah rasa takut dan terganggu tersebut dalam sebuah video berjudul Akal Raga yang memperlihatkan organ tubuh manusia. Rudiman mengatakan, pada satu sisi manusia tertarik untuk melihat penggambaran bagian tubuh terdalamnya. Namun di balik itu, ada rasa takut juga yang muncul saat menyaksikannya. Menurutnya, rasa takut itu muncul karena manusia akhirnya tahu, terdapat bagian tubuh yang berada di luar kontrolnya, tidak seperti tubuh bagian luar yang bisa dengan mudah "diakali" agar terlihat berbeda dari biasanya.

Video tersebut membuktikan bahwa rasa takut dan terganggu akan sesuatu bisa jadi hal menarik dalam karya seni, jika diolah dengan baik. Selain rasa takut, seniman juga mengolah perasaan jijik terhadap kotoran dan jamban dalam karya seni yang menarik untuk didiskusikan. Karya seni tersebut adalah South Korea's Toilet Themed Park yang dikenal dengan nama Mr. Toilet House. Taman adalah tempat yang biasa didatangi masyarakat untuk mendapatkan penghiburan karena menjanjikan hal-hal menarik dan indah untuk dipandang. Namun, $M r$. Toilet House justru mengekspos jamban dan kotoran dalam bentuk instalasi patung dan mural. Sebagian orang akan menilai bahwa itu adalah hal menjijikkan, namun tetap ditampilkan ke hadapan masyarakat. Oleh karena itu, artikel ini akan membahas latar belakang penciptaan karya-karya seni tersebut dengan menggunakan teori estetika sehari-hari (aesthetics of everyday life), yaitu estetika sosial dan teori disgust. Untuk kemudian, didapatkan alasan mengapa hal-hal yang biasanya disembunyikan dari masyarakat, justru dimunculkan ke permukaan.

\section{METODE PENELITIAN}

Objek dari penelitian ini adalah hal-hal yang bersifat aktual, dengan artian benar adanya serta dibicarakan oleh orang banyak. Oleh karena itu, metode yang tepat digunakan untuk penelitian ini adalah metode fenomenologi yang diusung oleh Hussrel. Smith (dalam Wattimena, 2013:193) menjelaskan bahwa teori fenomenologi-Hussrel ini sebagai suatu penyelidikan terhadap relasi antara kesadaran dengan objek luar, serta apa makna dari relasi itu. Fenomenologi menganalisis struktur dari persepsi, imajinasi, penilaian, emosi, evaluasi, dan pengalamn seseorang pada dunia luar. Proses analisis tersebut harus dilakukan menggunakan sudut pandang orang pertama.

Untuk mengetahui latar belakang penciptaan $M r$. Toilet House ini, diperlukan pengalaman dari sudut pandang orang pertama, yang betul-betul menyaksikan perubahan keadaan 
toilet umum korea dari tahun ke tahun. Orang tersebut adalah mantan walikota Suwon, Sim Jaeduck. Ia adalah orang yang mempelopori pembuatan taman bertema toilet tersebut. Setelah memperoleh data mengenai penciptaan taman toilet dengan segala instalasi di dalamnya, penulis akan menganalisis data tersebut dengan kacamata teori estetika sosial dan teori Disgust. Dengan demikian, akan didapatkan penjelasan tentang seberapa estetisnya South Korea's Toilet Themed Park ini.

Terkait mengumpulkan dan analisis data, penulis menggunakan sumber sekunder, di mana penulis menggunakan sumber literatur, berupa buku dan artikel di internet. Untuk data tentang pandangan Sim Jae-duck dan seluk beluk South Korea's Toilet Themed Park, sebagian besar penulis dapatkan dari website resminya di www.haewoojae.com. Selebihnya, didapatkan dari pengalaman pengunjung yang di bagian lewat video blog dalam kanal Youtube.

\section{HASIL DAN PEMBAHASAN}

\section{Mr. Toilet House and Park (Haewoojae, Toilet Culture Exibit Hall)}

Mr Toilet adalah sebutan untuk mantan Walikota Suwon, yaitu Sim Jae-duck. Ia lahir pada tahun 1939 dalam sebuah toilet di kediaman orang tua ibunya. Masyarakat menduga bahwa proses kelahiran ini yang menjadi alasan mengapa Sim Jae-duck menaruh perhatian khusus terhadap toilet. Ia adalah orang yang memprakarsai Toilet Culture Movement di Korea. Ia merekonstruksi rumahnya menyerupai toilet sebagai perayaan lahirnya the World Toilet Association. Rumah yang diberi nama Mr. Toilet House ini didesain oleh arsitek bernama Go Giwoong. Selesai dikontruksi pada tahun 2007. Setelah Sim Jae-duck meninggal pada tahun 2009, ia menyerahkan kepemilikan atas rumah dan area sekitarnya pada pemerintah kota Suwon. Selanjutnya, rumah itu dijadikan sebagai museum toilet dan area sekitar rumah dijadikan Toilet Culture Park. Di museum tersebut terdapat sejarah toilet di Korea dan negara lain. Masyarakat bisa mengunjungi dan belajar mengenai sanitasi di tempat ini secara gratis. Hal ini dilakukan pemerintah Suwon sebagai tanda hormat kepada Sim Jae-duck yang sudah berusaha untuk memperhatikan kebersihan toilet umum di kota tersebut semasa hidupnya. (Haewoojae.com)
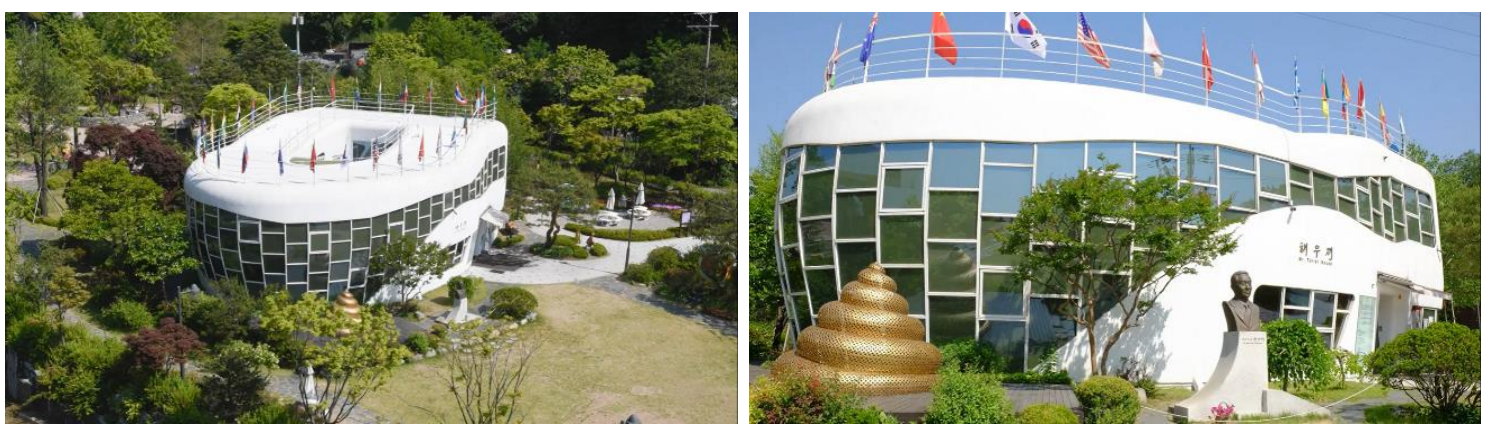

Gambar 1. Mr. Toilet House

Sumber: youtube.com, 2020 


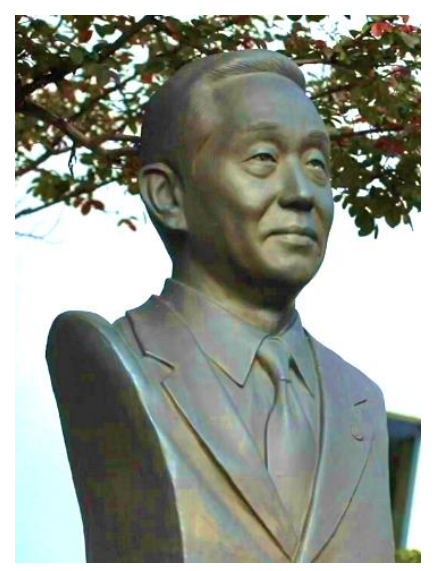

Gambar 2. Patung Mr. Toilet, Sim Jae-duck, yang di depan museum Sumber: youtube.com, 2020
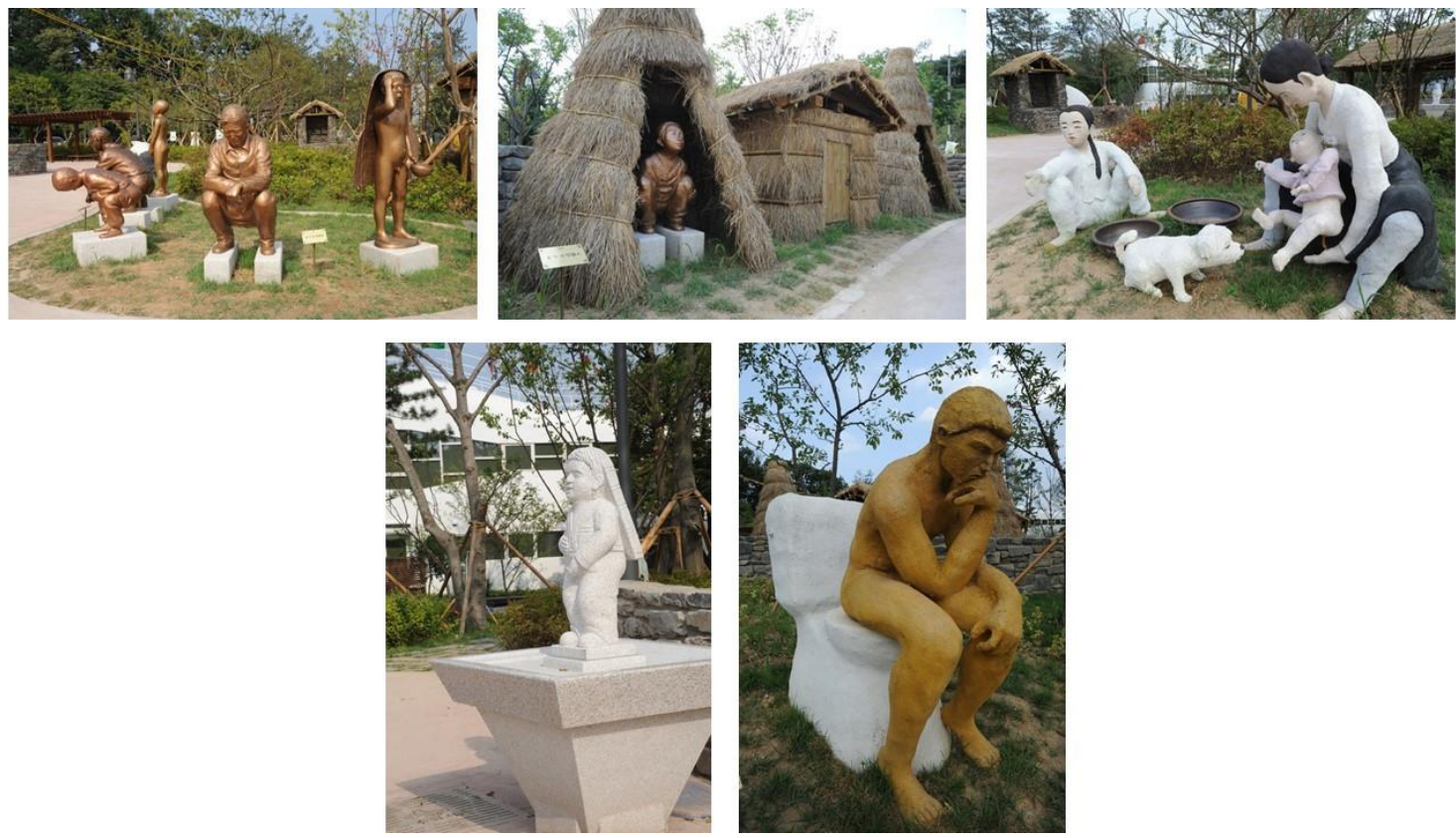

Gambar 3. Berbagai instalasi patung di area taman Sumber: www.haewoojae.com, 2012

Patung-patung pada gambar di atas adalah beberapa instalasi seni yang ada di area Toilet Culture Park. Pada dasarnya, ke semua gambar tersebut memperlihatkan kegiatan manusia dalam membuang kotoran dari dalam tubuhnya. Hanya saja, pose yang diperlihatkan di sana berbedabeda. Pose yang paling menarik perhatian adalah patung dengan pose merenung. Hal ini berkaitan dengan pernyataan yang disampaikan Sim Jae-duck dalam rapat World Toilet Association yang didirikannya pada tahun 2007, bahwa toilet bukan hanya tempat untuk melakukan relaksasi dan pembuangan. Lebih dari itu, toilet adalah tempat untuk melakukan introspeksi dan perenungan (McCurry, 2012). 

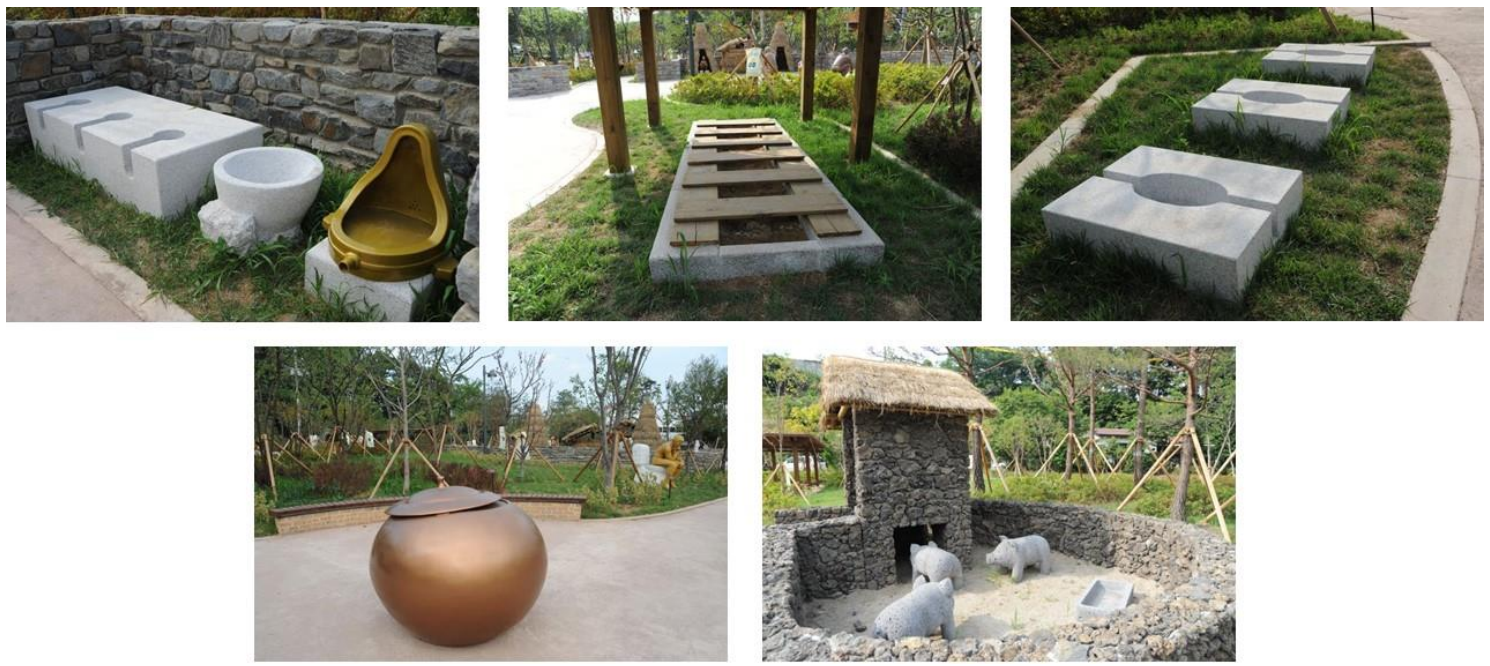

Gambar 4. Berbagai macam instalasi toilet dari berbagai masa Korea dalam area taman sumber: www.haewoojae.com, 2012

Gambar di atas menunjukkan berbagai macam bentuk jamban yang digunakan masyarakat korea dari tahun ke tahun. Yang paling mencolok di antara kelima gambar di atas adalah toilet yang terletak di atas kendang babi. Babi-babi yang ada di bawah toilet akan membersihkan kotoran yang turun dari sana. Itu adalah salah satu metode masyarakat korea pada zaman dahulu untuk membersihkan toilet mereka. Untuk jamban yang memiliki tangki, kotoran yang terkumpul akan dikumpulkan oleh petugas kebersihan.

Alonzo (2012), seorang fotografer professional di Korea Selatan, menyebutkan bahwa Sim Jae-duck ingin mengajak masyarakatnya untuk menjaga kebersihan toilet mereka. Senada dengan itu, McCurry (2012) juga melaporkan bahwa fasilitas yang ada di dalam museum juga instalasi di area taman memiliki pesan yang serius, yakni mengajak masyarakat untuk meningkatkan kesadaran akan kebersihan dan toilet umum. Sim Jae-duck mengatakan bahwa toilet memiliki arti yang lebih dari sekadar tempat pembuangan, namun toilet bisa diartikan sebagai tempat untuk menyelamatkan manusia dari penyakit. Menurutnya, ada banyak orang yang peduli dengan benda yang masuk ke dalam tubuh mereka, namun sedikit yang memikirkan benda yang mereka keluarkan dari tubuh. Baik yang masuk dan keluar, keduanya sama-sama penting.

Alonzo menambahkan bahwa dalam kebudayaan korea, kotoran berarti keberuntungan. Apabila seseorang bermimpi tentang kotoran, maka mereka bahwa itu adalah pertanda baik. Kotoran dan toilet adalah bagian dari budaya bagi masyarakat Korea. Mereka senang bicara soal kotoran. Itu terbukti dengan ada banyak jokes dan makanan yang diidentikkan dengan kotoran. Bagi mereka, itu hal biasa. Maka, dibukanya museum dan taman bertema toilet ini adalah hal yang perlu ditanggapi dengan senang hati.
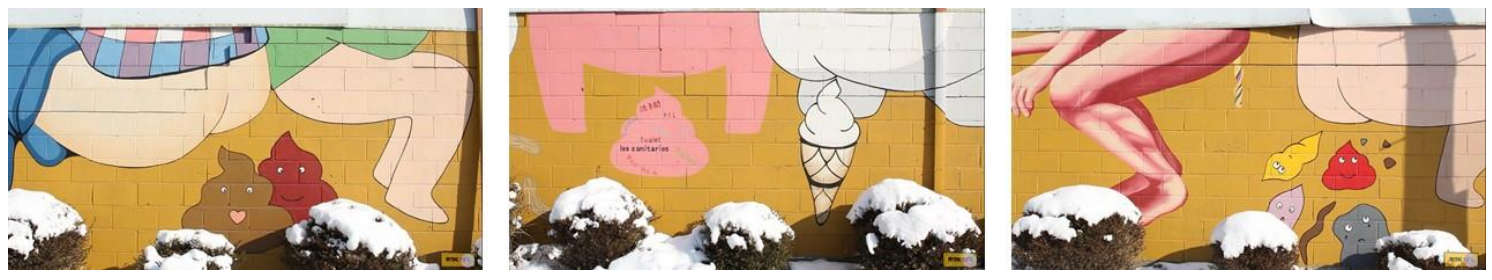

Gambar 5. Mural yang ada di sekitar Mr. Toilet House Sumber: Alonzo, 2012 


\section{Estetika Sosial dan Teori Disgust sebagai pisau analisis}

Estetika sosial pada dasarnya adalah estetika situasi, di mana akan sangat berhubungan dengan masalah-masalah konteksual. Estetika sosial juga sangat erat kaitannya dengan persepsi atau bahkan bisa dikatakan bahwa persepsi adalah hal mendasar bagi estetika sosial. (Berleant 2005 :30). Dalam beberapa karya seni yang mengusung ide estetika sosial ini mungkin tidak akan ditemukan siapa seniman yang menciptakan karya seni tersebut, sehingga masyarakat hanya akan dituntut untuk menilai karya seni itu tanpa harus mengetahui siapa orang dibalik penciptaannya. Dengan karya seni yang disuguhkan kepada khalayak ramai itu, para seniman akan mengajak para penikmat seni untuk memunculkan persepsi mereka masing-masing atas karya yang sedang dinikmatinya. Pada saat itulah para penikmat seni sedang berada dalam tataran mengapresiasi karya seni. Dengan adanya asumsi dan persepsi akan karya seni tersebut, para seniman juga akan meningkatkan kualitas dirinya dengan penilaian yang ada untuk menghasilkan karya yang lebih baik lagi. Lewat hubungan saling timbal-balik yang tanpa disadari inilah, situasi sosial mewujudkan diri menjadi sebuah estetika (Berleant, 2005: 31).

Situasi sosial dapat mewujudkan diri sebagai sebuah estetika ketika ada karakter-karakter estetika dominan yang muncul pada karya seni, yaitu: adanya penerimaan dari orang lain, banyaknya persepsi yang datang pada karya seni tersebut, adanya kegembiraan dan kebaruan, saling tanggap, adanya upaya melepaskan diri dari semua kungkungan terhadap penilaian dan apresiasi bebas (Berleant, $2005: 31$ ).

Gagasan mengenai estetika sosial menawarkan pendekatan yang khas, segar, dan menerangi hubungan manusia, baik dalam bentuk persahabatan, keluarga atau negara. Hal-hal yang demikian itu sangat fleksibel dan mudah beradaptasi dengan situasi kehidupan kita seharihari. Banyak masalah yang seringkali muncul silih berganti dalam kehidupan, maka estetika sosial hadir untuk menggantikan permasalahan tersebut dengan sesuatu yang menarik. Pada akhirnya, estetika sosial memberikan arti baru untuk sebuah toleransi, timbal balik, dan kesetaraan. Estetika sosial hendak membuat masyarakat yang benar-benar manusiawi dengan semua penilaian dan persepsi yang mereka punya (Berleant, 2005: 36).

Menjadikan manusia yang manusiawi dengan semua penilaian dan persepsi yang dimiliki akan memberi ruang bagi emosi tertentu, salah satunya rasa jijik (disgust). Kristeva (dalam Korsmeyer, 2004: 148) mengatakan bahwa ada pengalaman tertentu pada manusia yang dinilai sebagai ancaman dan mendorong emosi menjijikkan. Disgust didorong oleh objek yang batasnya tidak pasti dan berubah-ubah. Contohnya, hal-hal yang mengalami perubahan ke arah pembusukan.

Bertahun-tahun lamanya, emosi menjijikkan ini disembunyikan dari masyarakat. Namun, pada masa kontemporer sekarang ini, estetika mulai dimasuki pandangan-pandangan yang ingin menyatakan bahwa yang buruk (ugly) dan menjijikkan (digust) juga pantas untuk dipertontonkan dan dapat dinikmati oleh banyak orang. Estetika kontemporer mencoba untuk memunculkan halhal yang selama ini disembunyikan dan dianggap menjijikkan. Ketidak sukaan akan sesuatu yang menjijikkan (digust) berbalik menjadi rekognisi estetika yang positif. Ada anggapan bahwa rasa jijik dan muak (disgust) terhadap karya seni, dikarenakan orang tidak suka terhadap karya tersebut. Ini disebut penolakan (rejection). Yang dimaksud jijik atau muak (disgust) sebagai respons estetik adalah emosi/rasa jijik dan muak yang ditimbulkan oleh karya seni sebagai bagian dari pemahaman dan apresiasi. Di sini disgust adalah elemen positif dari pemahaman estetik. Disgust telah memasuki wilayah kontemporer estetik rasa suka dari berbagai arah. Julia Kristeva mengatakan bahwa terdapat pengalaman tertentu yang menampilkan ancaman terhadap diri yang muncul sebagai emosi terhadap yang menjijikkan (disgust) (Ekosiwi, 2013).

\section{Mr. Toilet House dalam Pandangan Estetika Sosial dan teori Disgust}

Jika melihat tanpa menggunakan kaca mata kuda, atau dengan kata lain melihat objek sebagaimana adanya tanpa tahu pesan yang ingin disampaikan seniman lewat objek tersebut, mungkin yang pertama kali terlintas dalam pikiran audiens ketika melihat pemandangan di area Mr. Toilet House adalah muak dan jijik (disgust). Begitu memasuki kawasan taman, instalasi 
kotoran, jamban, dan patung orang yang sedang membuang kotoran sudah ramai di depan mata. Ditambah dengan bentuk bangunan museum juga menyerupai sebuah kloset. Emosi muak dan jijik tentu tidak akan dapat dihindari. Persepsi-persepsi ini lah yang menjadi awal dari analisis estetika sosial.

Terlepas dari keputusan menolak atau menerima karya seni yang bersifat disgusting, secara tidak sadar akan ada persepsi-persepsi yang muncul dalam pikiran audiens ketika melihat karya instalasi bertema kotoran tersebut. Ada sederet pengalaman estetis yang hadir mengiri penglihatan. Pengalaman tersebut menggiring audiens kepada pengetahuan bahwa memang ada kebaruan di sini. Hadirnya benda-benda yang sebelumnya disembunyikan dan dianggap tidak pantas, coba untuk dimunculkan ke hadapan publik sebagai salah satu upaya untuk melepaskan diri dari segala pembatasan dan eksklusivitas yang menghambat apresiasi.

Audiens memiliki hak untuk menilai, mengapresiasi, bahkan menolaknya. Itu disebut sebagai keputusan estetis (aesthetics judgments). Namun, keputusan tersebut tidak bisa meniadakan pengetahuan yang didapatkan dari pengalaman estetis, sebab pengalaman tersebut melibatkan indrawi secara langsung, saat itu juga. Kemunculan rasa jijik setelah melihat sederet jamban dan kotoran, dalam estetika kontemporer, tidak dilihat sebagai hal yang negatif. Disgust adalah respons estetis yang ditimbulkan oleh karya seni sebagai bagian dari pemahaman indrawi dan apresiasi. Sebuah karya tidak menjadi rendah karena ditolak atau tidak disukai audiens. Sekalipun memunculkan emosi jijik, itu tetap disebut apresiasi. Yang perlu ditegaskan di sini, semua karya seni adalah setara, tidak ada pembatasan mana yang boleh dimunculkan, mana yang harus disembunyikan.

Alonzo (2012) mengatakan bahwa pembicaraan mengenai kotoran dalam budaya Korea adalah hal biasa. Kotoran dinilai sebagai realitas sehari-hari yang tidak perlu dihindari dalam pembicaraan. Sah-sah saja jika dimasukkan ke dalam gurauan kelompok bahkan diidentifikasi dalam bentuk makanan. Inilah mengapa teori estetika sehari-hari cocok digunakan dalam menganalisis $M r$. Toilet House sebagai museum dan toilet themed park pertama di dunia.

Dalam estetika sehari-hari ada yang disebut dengan estetika sosial. Estetika sosial menawarkan pendekatan yang khas dan segar dalam memandang sebuah karya seni. Mencari hubungan karya dengan relasi antar manusia dalam masyarakat adalah fokus yang ingin dicapai oleh estetika sosial. Relasi karya dengan kehidupan sosial masyarakat ini dapat dilihat secara jelas pada karya instalasi yang ada Mr. Toilet House. Museum beserta taman tersebut dibangun sebagai sebuah penghormatan kepada mantan walikota Suwon, Sim Jae-Duck, yang telah berjuang keras untuk memperbaiki kondisi toilet di kota itu. Lewat taman tersebut akan ada komunikasi yang baik antara seniman, penggagas, penikmat, dan yang diberi hormat. Melalui $M r$. Toilet House, pengunjung yang sebelumnya tidak tahu mengenai pembenahan toilet di kota Suwon akan mengapresiasi tindakan itu dan yang diberi hormat, walikota Sim Jae-duck (dalam hal ini adalah pihak keluarga) menjadi tergugah karena ada sebuah apresiasi akan apa yang telah diusahakan selama ini, maka seperti itulah situasi sosial mewujudkan hubungan manusia menjadi sebuah karya yang estetis.

\section{SIMPULAN}

Setelah panjang lebar diulas mengenai karya-karya seni yang hadir di ruang publik, ternyata tidak semuanya yang memberikan rasa nyaman dan ketergugahan bagi penikmatnya. Ada juga karya seni yang dapat mengusung tema yang selama ini disembunyikan ke hadapan publik, sekalipun itu menimbulkan pro dan kontra karena mengundang rasa jijik dan muak bagi sebagian orang. Seperti yang ditemui di Mr. Toilet House. Meskipun instalasi jamban dan kotoran di sana menimbulkan persepsi jijik pada sebagian orang, namun estetika sosial mengatakan bahwa karya tersebut tetap bernilai estetis. Estetika sosial yang sangat erat kaitannya dengan situasi dan konteks zaman, ingin memunculkan semakin banyak persepsi-persepsi estetis yang ada di tengah masyarakat tanpa harus takut akan pembatasan dan keeksklusifan apresiasi. Estetika sosial menyadari bahwa semua karya seni patut untuk ditampilkan dan diapresiasi.

Dari penelusuran terhadap karya-karya seni yang tidak biasa di Mr. Toilet House, penulis mengerti bahwa ketertarikan tidak selalu muncul karena keindahan. Sekalipun rasa muak dan jijik 
yang muncul saat melihat sebuah karya seni, namun bukan berarti karya seni tersebut tidak menarik, sehingga direndahkan. Ketika suatu karya seni mampu memberikan sebuah efek pada penikmatnya dengan adanya penilaian dan persepsi dari mereka, maka di sanalah penulis melihat bahwa karya seni tersebut berhasil menyampaikan pesannya.

\section{DAFTAR PUSTAKA}

Alonzo, N. (2012, 10 Desember). Mr. Toilet House 해우재 [Life in South Korea \#38] [Online]. Diakses dari https://www.youtube.com/watch?v=L4CTmwwyVB0

Ekosiwi, E. K. (2017). Permasalahan Etis dalam Estetika dan Pendidikan Filsafat Seni. Respons. 22(01): 63-87

Ekosiwi, E. K (2013). Difficult Pleasures - Sublimity and Disgust. (Modul). Depok: Universitas Indonesia

Korsmeyer, C. (2004) Gender and Aesthetics: an introduction. UK: Routledge.

Light, A. \& Smith, J. M. (Penyunting). (2005). The Aesthetics of Everyday Life. New York: Columbia University Press

McCurry, J. (2012, 9 November). South Korea's toilet museum: a place for contemplation. [Online]. Diakses dari https://www.theguardian.com/world/2012/nov/09/south-koreatoilet-theme-park

Rudiman, A. F. \& Durahman, D. H. (2014) Akal Raga. Jurnal Tingkat Sarjana Bisang Seni Rupa dan Desain. Bandung: ITB

Wattimena, R. A. A. (2013). Berbagai Bentuk Metode Berfilsafat: Sebuah Tinjauan Historis Sistematis dari Masa Yunani Kuno sampai Postmodernisme. Dalam Reza A. A. Wattimena (Penyunting), Metode Penelitian Filsafat (hlm. 127-241). Yogyakarta: Kanisius 